\title{
Delimiting a saline water zone in Quaternary fluvial-alluvial deposits using transient electromagnetic: a case study in Punata, Bolivia
}

\author{
Andres Gonzales Amaya ${ }^{1,2}$ ( ) Joakim Mårdh ${ }^{1}$. Torleif Dahlin ${ }^{1}$
}

Received: 30 June 2017 / Accepted: 29 December 2017 / Published online: 19 January 2018

(c) The Author(s) 2018. This article is an open access publication

\begin{abstract}
The semiarid Punata alluvial fan is located in the central part of Bolivia. The main activity of this region is the extensive agriculture, and groundwater is the main water supply. Local villagers who use groundwater reported that in some places groundwater has a salty taste. In order to investigate the origin of this problem, several TEM soundings were performed in the study area, and they were complemented with ERT surveys. The results show top layers with resistivity values ranging from 30 to $200 \Omega \mathrm{m}$ and a bottom layer with resistivity values ranging from 1 to $20 \Omega \mathrm{m}$, which might be interpreted as the main aquifer and a layer with high clay content, respectively. Between the top and bottom layer, a transition zone with saline water has been identified, with resistivity values ranging from 0.1 to $1 \Omega \mathrm{m}$. The origin of this closed-basin brine might be a product of the evaporation of paleolakes during the lower Pliocene, where saline clays were deposited. This study demonstrated the effectiveness of TEM sounding for mapping very low resistivity zones such as saline water.
\end{abstract}

Keywords Geophysics · Transient electromagnetic · Saline water · Groundwater characterization

\section{Introduction}

In many parts of the world, agriculture is the main social and economic activity. The most common way of irrigation in agriculture is by using surface water, e.g., rainfall, rivers, and lakes. However, climate change has affected the water budget in many regions of the world leading to severe shortages. The study by IPCC (2007) forecasted that climate change in the upcoming years will affect rainfall patterns, river flows, and sea levels all over the world. In many arid regions, there is an expected decrease in rainfall of $20 \%$ or more. Therefore, groundwater can be an important alternative water source, and this importance becomes more evident in arid and semiarid areas, where there is already a deficit in the surface water supply. However, knowledge of the aquifer characteristics such as layering and chemical composition is needed for a sustainable management of groundwater.

Andres Gonzales Amaya

andres.gonzales@tg.lth.se

1 Engineering Geology, Lund University, Box 118, 22100 Lund, Sweden

2 Laboratorio de Hidráulica, Universidad Mayor de San Simón, Av. Petrolera km 4.2, Cochabamba, Bolivia
The Punata alluvial fan in Bolivia is a semiarid area, and this region has a low average rainfall of $350 \mathrm{~mm} /$ year and a potential evapotranspiration greater than $800 \mathrm{~mm} /$ year leading to a water deficit in the area (Montenegro and Rojas 2007). In order to fill this deficit in water supply, the local people started to drill boreholes, and the number of wells has increased considerably in the recent years. The monitoring of the groundwater level shows a decreasing trend of the water table, and probably, the main reason for this decline is due to the fact that groundwater extraction has exceeded the natural recharge during the last few years (Gonzales Amaya et al. 2016). Furthermore, the drilling of the wells is performed without any technical criteria due to the lack of local information about geology and hydrogeology, which might cause further problems such as low yield and/or poor water quality. Local reports claim that in some boreholes the groundwater quality is unsuitable for drinking water and irrigation purposes due to high salinity. In these boreholes, the electrical conductivity (EC) can be higher than $2400 \mu \mathrm{S} / \mathrm{cm}$, and it is associated with the high concentration of salts. Some reports indicate that groundwater quality can vary in short distances. For instance, in borehole P179 groundwater salinity can be as much as $3 \%$, but $100 \mathrm{~m}$ away the groundwater sampled in borehole $\mathrm{P} 177$ has freshwater quality (refer to Fig. 1a for borehole locations). This change 

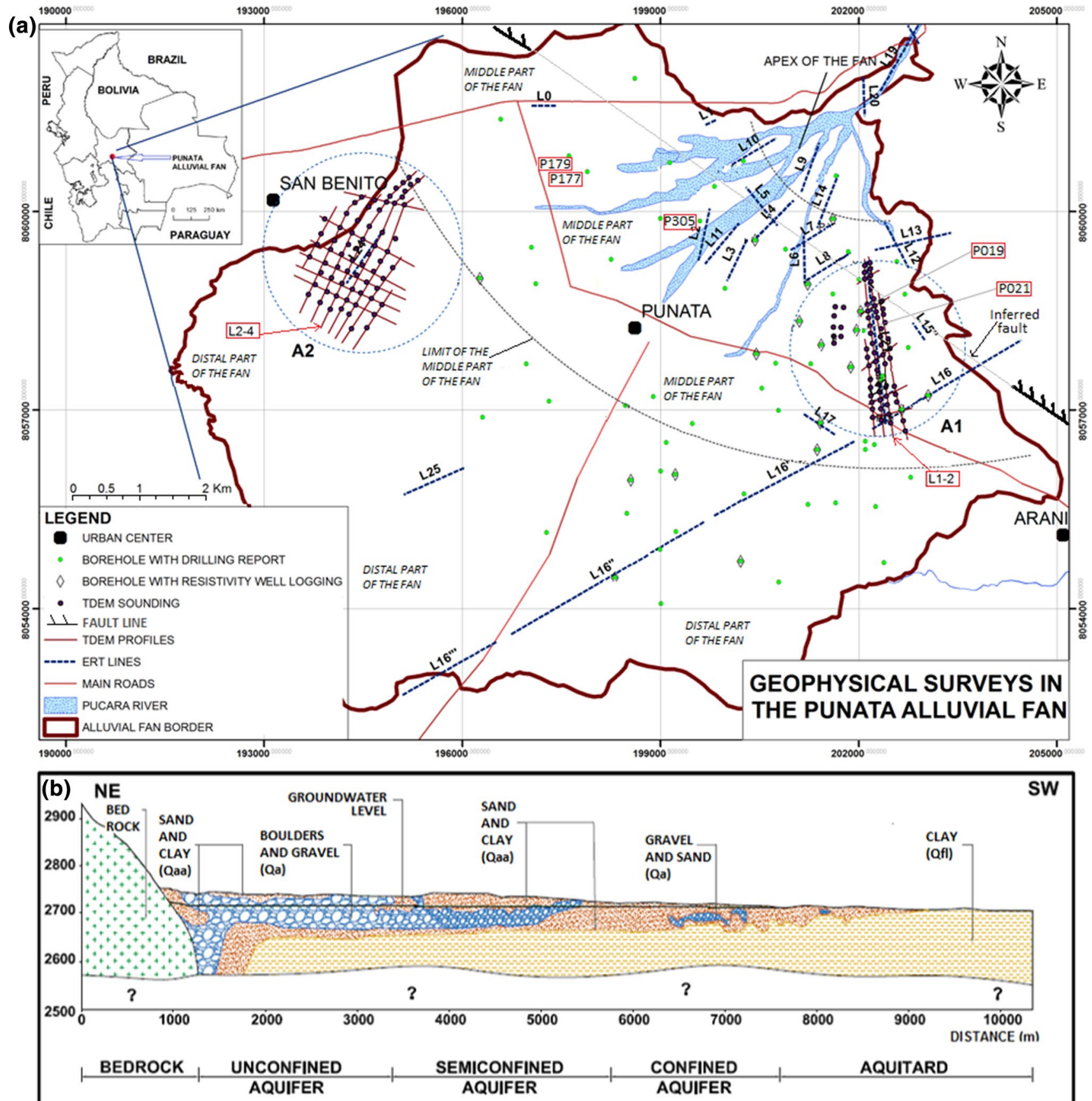

Fig. 1 a Study area and location of the geophysical surveys. TEM surveys are divided in two areas encircled in pointed lines, area 1 (A1) and area 2 (A2). b Cross section of the Punata alluvial fan, modified from Gonzales Amaya et al. (2016)

in groundwater quality might be explained by the extraction of groundwater from different depths.

In order to determine the depth of these saline water zones, geophysical methods were applied in the Punata alluvial fan. The study by Gonzales Amaya et al. (2016) used electrical resistivity tomography (ERT) and normalized chargeability to refine the hydrogeological conceptual model. However, results from these surveys have not showed layers with very low resistivity values, i.e., lower than 10 $\Omega \mathrm{m}$, which might be typical for saline water. Consequently, other geophysical approaches more sensitive to low-resistivity zones must be used such as electromagnetic methods.

The transient electromagnetic (TEM) is a ground-based geophysical method and has been used in many studies with environmental applications, e.g., Fitterman and Stewart (1986), Danielsen et al. (2003), Goldman et al. (1988), 
Guérin et al. (2001), and Nabighian and Macnae (1991). The TEM method provides an excellent resolution of conductive materials at large depths and highlights the contrast between high- and low-resistivity materials (Christensen and Sørensen 1998). The aim of the present study is the application of TEM in combination with available reference data in Quaternary alluvial-fluvial deposits to delimit the depth and thickness of zones with saline water. This information is valuable for further planning and policies for sustainable and appropriate groundwater exploitation.

\section{Study area}

The Punata alluvial fan is located in the central part of Bolivia (Fig. 1a), in the department of Cochabamba between the coordinates latitude $17.59-17.49^{\circ} \mathrm{S}$ and longitude $65.90-65.78^{\circ} \mathrm{W}$. The study area is surrounded by a mountainous massif, whose peaks can reach $3500 \mathrm{~m}$ above sea level (m.a.s.l.), and the area is gently sloping from northeast to southwest (Fig. 1b). The extension of the alluvial fan is around $90 \mathrm{~km}^{2}$. The main urban center is the Punata city in the middle of the fan. The regional geology is described by UNDP-GEOBOL (1978), GEOBOL (1983), and May et al. (2011). The basement of the study area is formed of Ordovician and Silurian rocks. The valleys are filled with unconsolidated sediments from the Quaternary; the main units are: fluvial, lacustrine, fluvio-lacustrine, and colluvial-alluvial sediments. These units form terraces on riverbanks, beds, and alluvial fans at the mouths of creeks and rivers. During the lower Pliocene, due to the lifting of the mountain massif, tectonic valleys and enclosed lakes were created. The weather in this period was predominately dry, and saline material with high clay content was deposited (UNDP-GEOBOL 1978).

The deposition of Quaternary sediments in the Punata alluvial fan is as follows (Fig. 1b): (1) In the apex of the fan, fluvial $\left(Q_{\mathrm{a}}\right)$ and terrace $\left(Q_{\mathrm{t}}\right)$ sediments were deposited. These deposits are mainly composed of coarse material, varying from boulders to sand. (2) The middle of the fan is a transitory zone from alluvial $\left(Q_{\text {aа }}\right)$ to fluvio-lacustrine $\left(Q_{\mathrm{fl}}\right)$ deposits. The grain size of these deposits ranges from gravel to clay and silt. (3) The distal part of the fan is mainly composed of fluvio-lacustrine deposits $\left(Q_{\mathrm{f}}\right)$. These deposits are mainly formed of clay and silt.

\section{Methods}

\section{Time domain electromagnetics}

The TEM is a controlled source method which measures several transient electromagnetic field diffusions (Goldman and Neubauer 1994; Guérin et al. 2001; Nabighian 1991). The principle of this method is that a current is alternately turned on and off. Then, the induced electric field will produce a primary proportional and perpendicular magnetic field. Changes in the magnitude of magnetic fields induce electromotive force (emf). Fast changes in the magnitude of magnetic fields will yield greater emf, while slow changes will induce smaller emf. As the emf is propagated into the ground, it will induce eddy currents, and these currents will produce a secondary magnetic field. This secondary magnetic field has an amplitude that decreases with time and will depend on the ground resistivity. Soils with high resistivity will yield magnetic fields with high initial amplitudes and quick decays, while soils with low resistivity will have an opposite behavior (Christiansen et al. 2009; Fitterman and Stewart 1986; Guérin et al. 2001).

The most common way for retrieving TEM data is by placing a square transmitter coil on the ground. After the electrical current is induced, the secondary magnetic field (b) is measured by a receiver coil. These measurements are conducted in discrete time intervals $(\mathrm{d} b / \mathrm{d} t)$ after transmitted current termination. With longer acquisition time (i.e., late gates), information from deeper formations is retrieved, while with the early times (i.e., early gates) information of layers close to the surface is retrieved (Christiansen et al. 2009; Mills et al. 1988).

This method is sensitive to natural background noise such as power lines, lightning storms, and radio antennas. In order to minimize the error from noise, every TEM sounding is composed of a large number of transients generally about 1000-10,000. These transients are stacked, and a mean signal is obtained. The depth of penetration in the TEM method is affected mainly by three factors (Christiansen et al. 2009; Fitterman and Stewart 1986): the resistivity of the different geological formations, the intensity of the background noise, and the moment of the transmitter. Hence, the only practical way for increasing the depth of penetration is often by increasing the moment of the transmitter.

A high density of TEM soundings will assist in 1) improving the resolution of geological structures, and 2) identification of possible malfunctions of the instrument, capacitive induced coupling from the instrument, and background noise, so that later the corrupt soundings or noise can be identified and dismissed (Christiansen et al. 2009).

\section{Fieldwork and data processing}

The TEM soundings were carried out with an ABEM WalkTEM. A transmitter loop of $50 \times 50 \mathrm{~m}$ was used for all the soundings. Two central receiver loops were used: the inner one of $0.5 \times 0.5 \mathrm{~m}(\mathrm{RC}-5)$ and the outer one of $10 \times 10 \mathrm{~m}$ (RC-200). The RC-5 has a total receiver area of $5 \mathrm{~m}^{2}$, with 20 turns internally. The RC-200 has a total receiver area 
of $200 \mathrm{~m}^{2}$, with two turns internally. Both receiver antennas measure soundings with high moments (HM) and low moments (LM). The HM allows to retrieve information from deeper levels with poor resolution near to the surface, while the LM allows to retrieve information with good resolution in levels close to the surface, but with a poor depth of penetration. Two batteries of $12 \mathrm{~V}$ each in series were used as a power source, which allowed a current injection of 18A. A total of 128 TEM soundings were performed in two different areas: area 1 (A1) and area 2 (A2), refer to Fig. 1a, with an approximately 150-m separation between each sounding. The inversion process of the TEM soundings was performed in the SPIA version 2.1.3, while the interpolation and creation of 2-D profiles were performed in Workbench version 5.2.2. Both programs are distributed by Aarhus GeoSoftware.

The inversions were made by selecting the LM from RC-5 and the HM from RC-200. The RC-5 has a better resolution near the surface, while RC-200 reaches deeper levels. This was done for all the sounding of A1 and for soundings 1-40 in A2. For soundings 41-68 in A2, only the RC-5 antenna was used due to logistical problems in the field. Therefore, for the latter soundings both HM and LM from RC-5 were used in the inversions (Mårdh 2017). SPIA software allows the user to perform two types of inversions: the layered model which usually uses 3-5 layers, and the smooth model which predetermined uses 20 layers. The latter provides a model curve with a smooth appearance and greater vertical resolution, but the identification of abrupt changes in resistivity is weak. On the other hand, the layered model will allow the user to evaluate sharp resistivity transitions but will not detect minor variations in resistivity. The evaluation of the inversion models is made by the data residual, and in order to obtain a data residual as low as possible, the starting model might be modified. The modifications are made by changing specific layer thicknesses and resistivity ranges when there is a priori known information. This procedure may produce equivalent solutions (Fig. 2b), and the best equivalent solution might be the one with a residual value at least less than one. The final 1-D inverted models were exported to Workbench where 2-D profiles were created. The option of kriging with exponential variogram was used for interpolating the 1-D models to 2-D profiles.

Finally, several ERT surveys were performed in the Punata alluvial fan by Gonzales Amaya et al. (2016). Some of these profiles are within and close to the TEM soundings (refer to Fig. 1a). In order to complement the ERT surveys, some additional profiles were performed within A1 and A2. In addition to ERT surveys, data from drilling reports and geophysical well loggings were collected. The comparison between resistivity values from the different methods can assist in the interpretation and validation of the TEM results.

\section{Results and discussion}

Figure 2 a shows the typical trend of apparent resistivity obtained from the TEM soundings in A2. In all the soundings at later stages, the apparent resistivity decreases, which is an indicator that layers with low resistivity are reached.
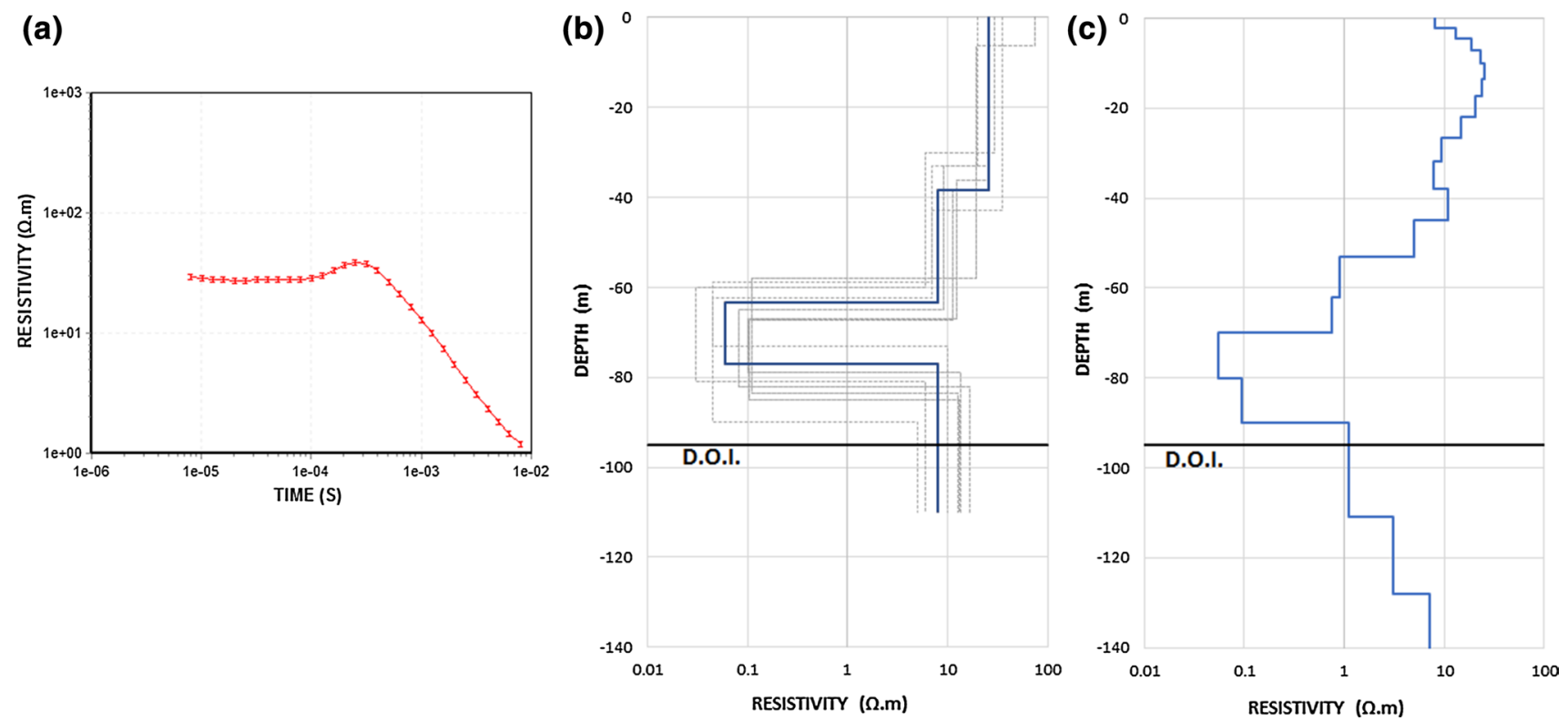

Fig. 2 Example of TEM soundings inversion process in A2, within a same data set. a Apparent resistivity versus acquisition time. b Layered solution, equivalent solutions in dashes lines, and model with the best fit in solid line. c Smooth solution with 20 layers interpretation 
In Fig. $2 b$, it is displayed that for each sounding there are several equivalent solutions (dashed lines). This means that different resistivity values and layer thickness can yield the same response of the apparent resistivity. After performing several inversions, a final solution (solid line) is achieved. The parameter used for selecting the best solution is the residual data, which must be smaller than one. Figure $2 b$ and $\mathrm{c}$ shows the layered and smooth inversion models, respectively. Both models highlight a low-resistivity layer at approximately $-70 \mathrm{~m}$, and both yield approximately the same depth of investigation (DOI). The DOI is basically limited to background noise, resistivity of the ground, and the moment of the current. In this study, the bottom layers are dominated by a high clay content layer with low resistivity, which dissipates the electromagnetic signals and reduces the DOI.

All the TEM sounding curves show a trend of decreasing resistivity with depth. Generally, in A1, the resistivity in the top layers is between 100 and $200 \Omega \mathrm{m}$, while in A2 the values of resistivity on the top layers are lower, e.g., 20-60 $\Omega \mathrm{m}$. In both areas at the bottom of the soundings, the resistivity values are similar and range from 1 to $20 \Omega \mathrm{m}$. However, the TEM soundings have detected a transition zone between the top and bottom layers, where the resistivity can be as low as $0.1 \Omega \mathrm{m}$. This is observed in Fig. 2b, c at a depth close to $70 \mathrm{~m}$. These low-resistivity values might be associated with high concentrations of salts, e.g., $\mathrm{Na}^{+}$and $\mathrm{Cl}^{-}$. Figure 3a displays the plot of electrical conductivity (EC) and resistivity versus the concentration of $\mathrm{Na}^{+}$and $\mathrm{Cl}^{-}$obtained from 45 water samples within the Punata alluvial fan aquifer and surroundings. From this figure, it is observed that the increase in the concentration of these ions increases the
EC (or decreases the resistivity) of the water samples. The study by UNDP-GEOBOL (1978) reported EC for borehole P305 (refer to Fig. 1a) of $97 \mu \mathrm{S} / \mathrm{cm}(\sim 103 \Omega \mathrm{m})$ between 0 and $100 \mathrm{~m}$ depth, $6000 \mu \mathrm{S} / \mathrm{cm}(\sim 2 \Omega \mathrm{m})$ at $150 \mathrm{~m}$ depth, and $30,000 \mu \mathrm{S} / \mathrm{cm}(\sim 0.3 \Omega \mathrm{m})$ at $250 \mathrm{~m}$ depth, which indicates an increase in salinization and EC with depth. The increase in salt content with depth will lead to a decrease in the bulk resistivity of the soil. The high concentrations of salts might be explained due to the fact that during the lower Pliocene the climate was mainly hot and dry, and paleolakes in the regions were evaporated. During this evaporation, period clay with high content in salts was deposited. Studies about the evolution of closed-basin brines indicate that there are commonly paths of development of brines (Eugster and Hardie 1978; Hardie and Eugster 1970), and these paths can be observed in the study area (refer to Fig. 3b). In the study area, the evolution of the brine layer might have occurred when freshwater acquired solutes by mixing water through saline deposits. In Fig. 3b, freshwater evolves from a carbonate type to chloride type; according to Hardie and Eugster (1970), the brines in the Punata alluvial fan are of the carbonate-chloride type, probably due to the partial dilution of gypsum. The occurrence of brines, which is supported by the chemical analysis, explains the very low resistivity in the deeper layers of the Punata aquifer.

Figure 4 shows the resistivity values acquired from three different methods: TEM, ERT, and borehole resistivity at two different locations. The normalized chargeability curve is also included in the same plot. There is a good agreement between all the methods. In all the cases, the resistivity values decrease with depth. However, ERT results seem to be less sensitive to high conductive layer or have less capability (a)

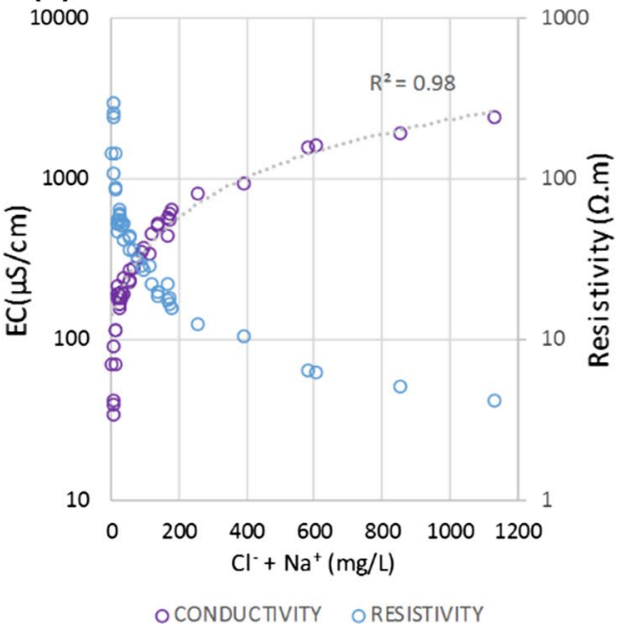

Fig. 3 a Groundwater electrical conductivity and resistivity versus the concentration of chloride and sodium. Note the logarithmic scale for both vertical axes. b Evaporation paths and type of brines. Open (b) ANIONS

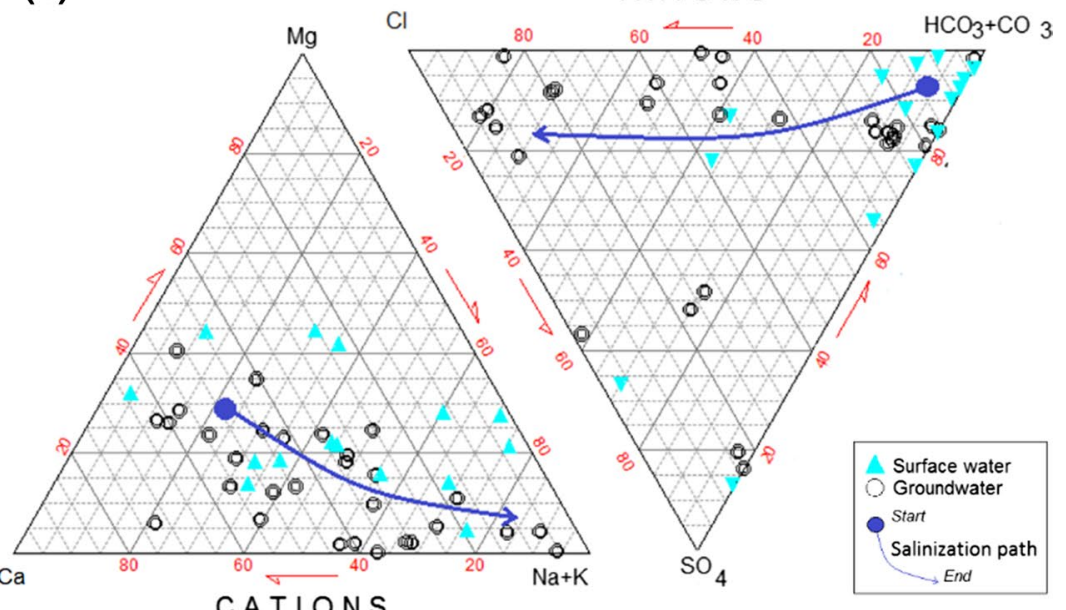

CATIONS circles stand for groundwater samples, and filled triangles represent surface water samples 


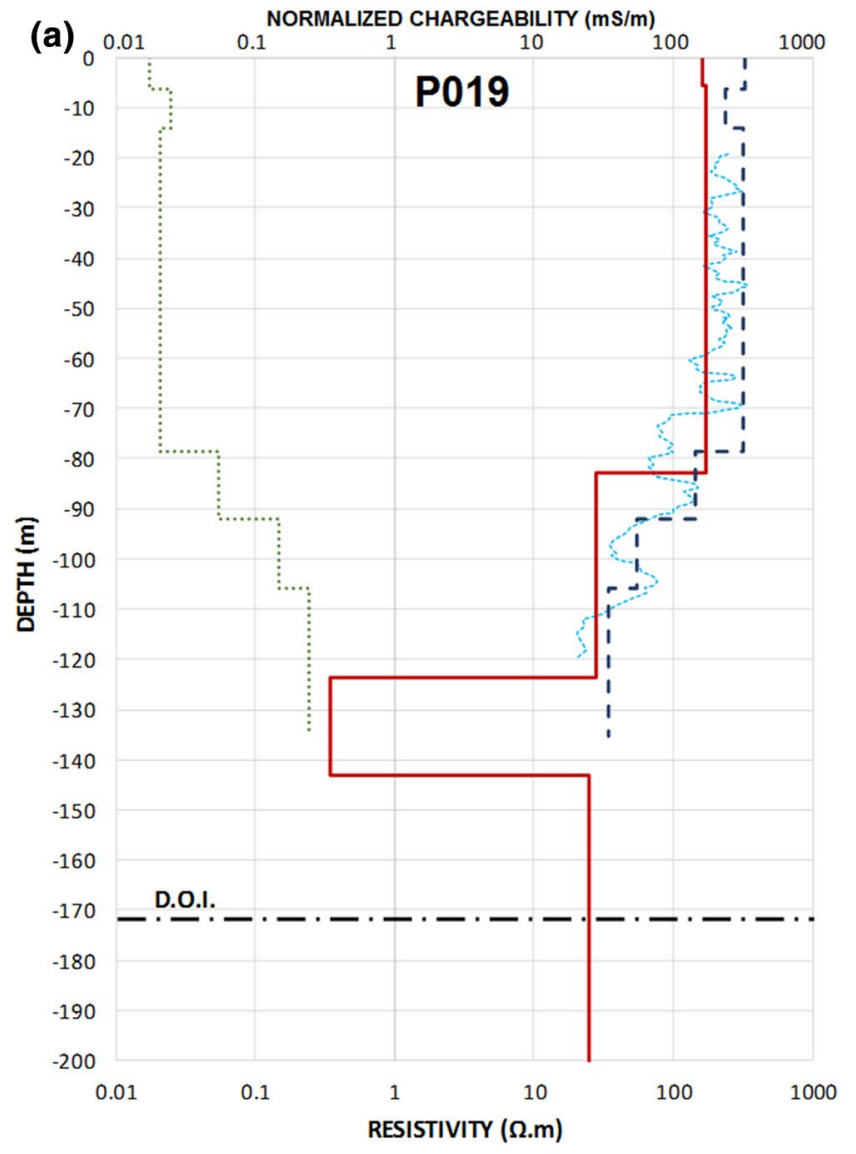

BOREHOLE RESISTIVITY P019 - TEM RESISTIVITY
....... NOR MAUZED CHARG EABILITY - - - ERT RESISTIVITY

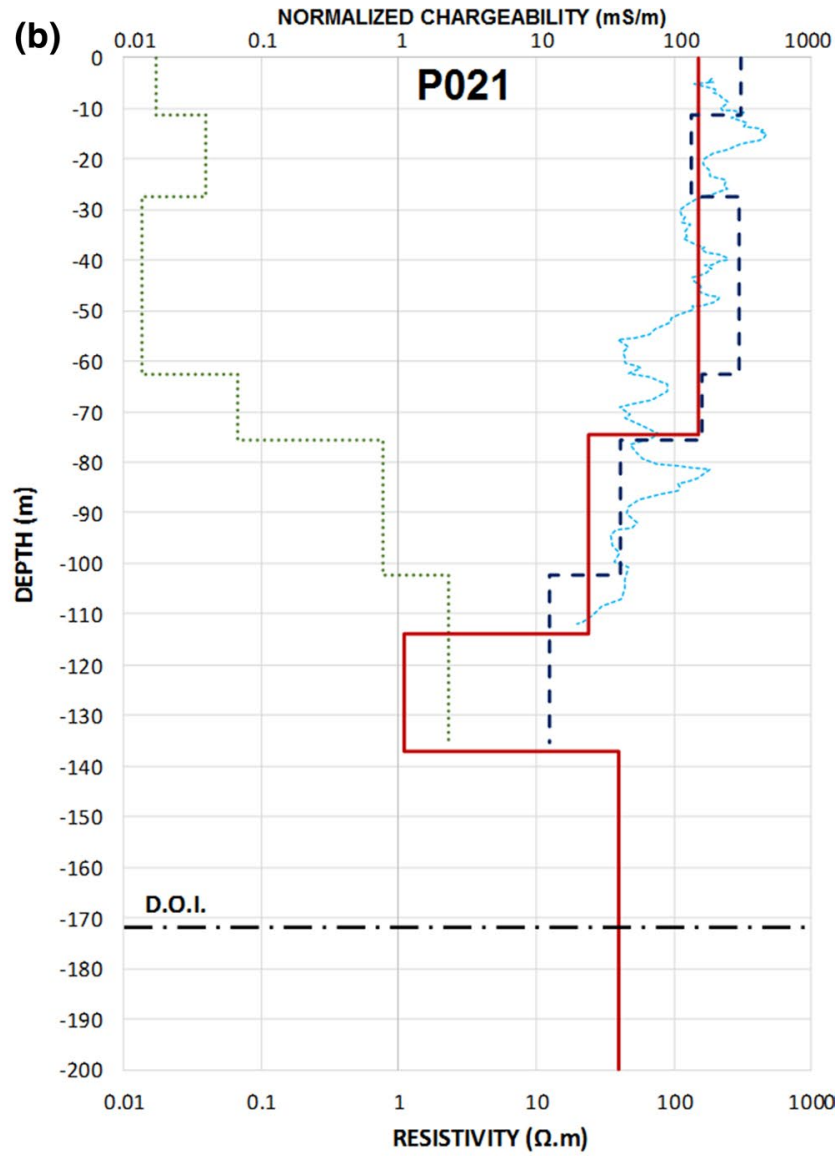

B.-.-. BOREHOLE RESISTIVITY P021 TEM RESISTIVITY
........ NORMALIZED CHARGEABILITY

- - - ERT RESISTIVITY

Fig. 4 a and b Comparison of normalized chargeability and resistivity values from ERT, TEM, and borehole logging, acquired in wells P019 and P021, respectively (refer to Fig. 1a)

to resolve them, but TEM soundings highlight these layers. This is observed in Fig. 4a, b, where at depths between 120 and $140 \mathrm{~m}$, TEM models have values of resistivity close to $1 \Omega \mathrm{m}$, while ERT values are close to $10 \Omega \mathrm{m}$. Another explanation why ERT is unable to resolve the low-resistivity layers is because of the layout of the performed surveys (i.e., spread of $800 \mathrm{~m}$ with $10-\mathrm{m}$ electrode separation). With this layout, the maximum depth coincides with the depth of the brine layers. Since the accuracy and resolution decrease with depth in ERT (Dahlin 2001; Loke 2010; Loke et al. 2003), this might have affected the ability of ERT to resolve the low-resistivity layers. Furthermore, values of normalized chargeability increase with depth. High values of normalized chargeability might be related to sediments with high clay content, while soil with uniform particle size of sand and/or gravel might yield lower values of normalized chargeability (Alabi et al. 2010; Revil et al. 2015; Slater and Lesmes 2002). Therefore, the high values of normalized chargeability in the Punata aquifer are partially explained by the high clay content. However, as it is mentioned above, the very low values on resistivity might be explained just by the presence of brines.

The DOI often varies between ERT and TEM surveys. In the first case, it depends on the separation of electrodes, while in the second case it depends on the transmitter loop moment. Figure $4 a$, b shows that the effective depth of penetration in TEM is around $170 \mathrm{~m}$. The depths of investigation in A1 are between 150 and $200 \mathrm{~m}$, while in A2 they are around $80-100 \mathrm{~m}$. This difference is because of the fact that the layer with high clay content in A2 is shallower, which quickly dissipates the electromagnetic signals. When all the final models have been estimated with the SPIA program, these are exported into Workbench. The latter was used for generating 2-D profiles. For A1, a total of 9 profiles were created, while for A 2 a total of 14 profiles were made.

Figure 5 shows two example profiles obtained from the 1-D soundings, and in both cases different geological units can be interpreted. The interpretation was made with the lithological information from wells located close to the lines. The main material of each layer is shown by their 

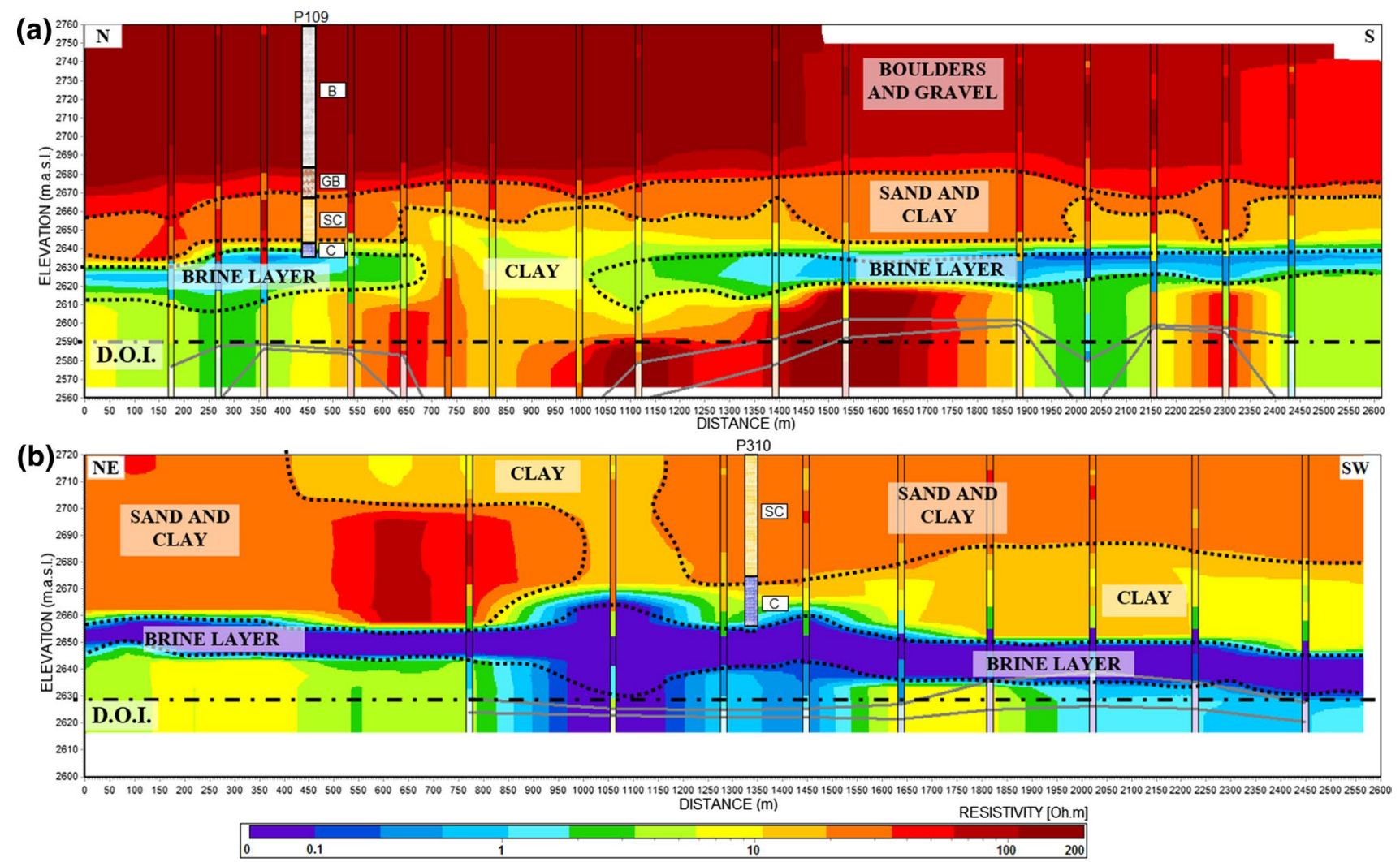

Fig. 5 Resistivity profiles with geological interpretation derived from TEM soundings. Lithological descriptions from available boreholes close to the surveys are included too. a Profile L1-2 located in A1. b

initial letter (i.e., B stands for boulders, $\mathrm{G}$ for gravel, $\mathrm{S}$ for sand, and C for clay). The profile L1-2 (refer to Figs. 5a, 1a) is located in A1. This area is close to the apex of the fan, where the material is coarse in the top layers and decreases in size with depth. The same pattern occurs with resistivity which decreases from $200 \Omega \mathrm{m}$ in the top to less than $20 \Omega \mathrm{m}$ in the bottom. This profile shows a thicker layer of higher resistivity in the northern than in the southern part. As it is mentioned above, this is because close to the fan apex the rivers have more energy leading to deposition of coarser material, but further away from the apex the river energy diminishes, and finer material is deposited. In L1-2 profile approximately at a depth of $140 \mathrm{~m}$ (or 2620 m.a.s.l.), there is a layer with very low resistivity, which may be related to the presence of brines. The resistivity of this saline water is slightly lower than $1 \Omega \mathrm{m}$.

In Fig. 5b, the profile L2-4 is shown, and the top layer seems to be dominated by sand and clay and clay solely. The high clay content in this profile is due to the fact that A2 is located in the distal part of the Punata fan, where the Quaternary sediments are of the lacustrine type. In A2, the layer interpreted as a brine has lower resistivity than in A1, and this might be explained by the less inflow of fresh water
Profile L2-4 in A2. Both geoelectrical sections indicate a saline layer with resistivity values lower than $1 \Omega \mathrm{m}$

to the zone, which can dilute the salts and consequently decrease the resistivity. The brine is located approximately at depths of $70 \mathrm{~m}$ (or $2650 \mathrm{~m}$.a.s.1.), and the resistivity of this zone can be as low as $0.1 \Omega \mathrm{m}$.

Figure 6 displays the horizontal resistivity distribution for both areas. The separation between each horizontal map is not to scale. In Fig. 6a, the horizontal resistivity distribution of A1 is displayed. As expected, high-resistivity materials are found in the top layers, and the values decrease with depth. Close to 2655 m.a.s.l., a low-resistivity zone is detected, with values around $1 \Omega \mathrm{m}$, and attributed to be brine deposits. When the deeper levels are reached in A1, it would be expected to locate a low-resistivity zone caused by the lacustrine deposits; however, a zone with high-resistivity values was detected (indicated in the lowest level of Fig. 6a). This high-resistivity zone is unlikely to be composed of coarse material such as sand or gravel since the brine is not sinking. Therefore, these high values of resistivity might be caused by a fault where bedrock is protruding through the lacustrine layer. The local geology shows fault lines that end in the Quaternary deposits (refer to Fig. 1a); however, if these lines are extrapolated, they cross over the area with high resistivity. Furthermore, the local geology indicates that 


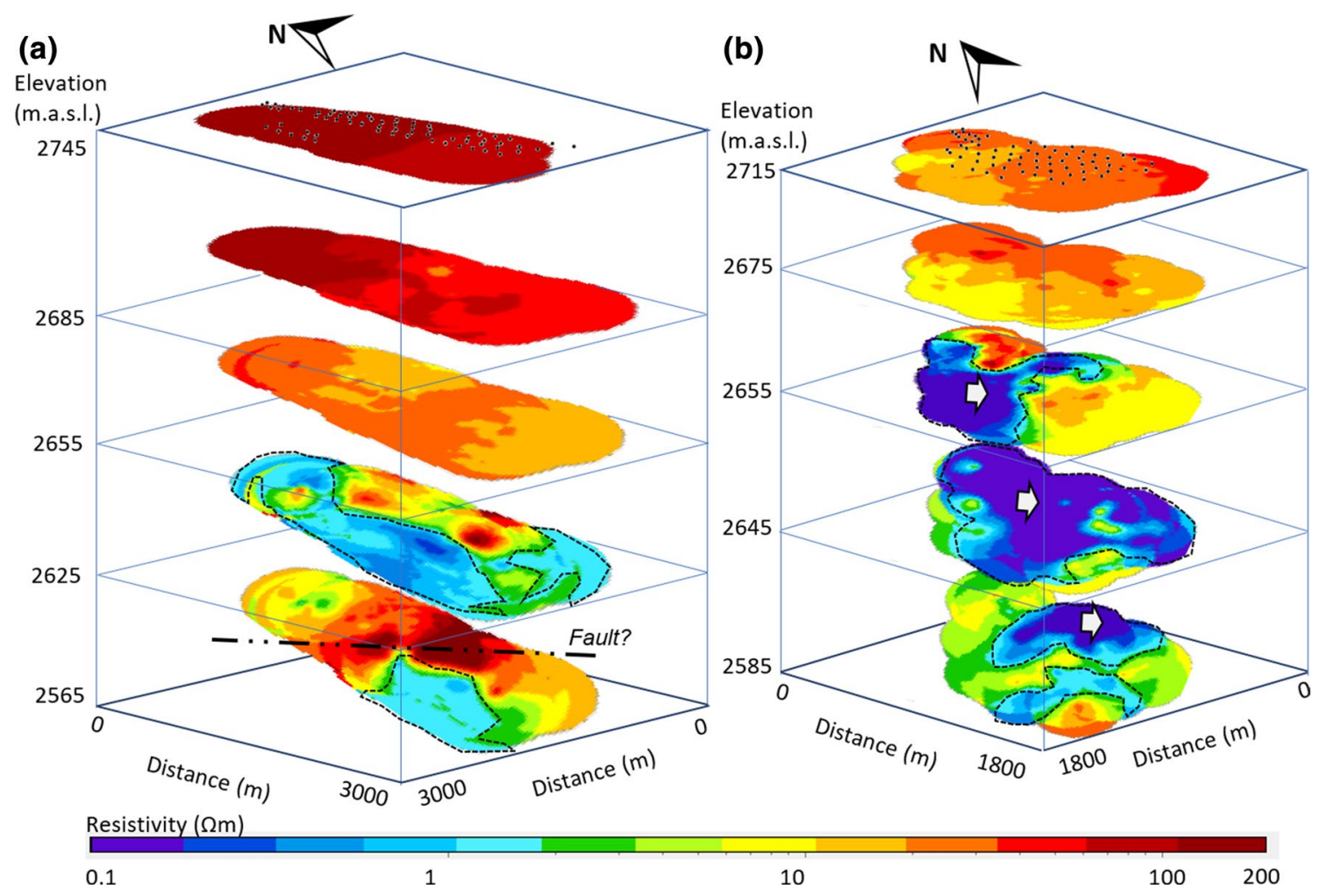

Fig. 6 a and b Horizontal resistivity maps at different depths for A1 and A2, respectively. Note the different scales in depth and distance. Enclosed areas with dashed lines are zones interpreted as saline

San Benito formation is underlying the Quaternary deposits, and this formation is composed of quartzitic sandstone with resistivity values close to $200 \Omega \mathrm{m}$ (GEOBOL 1983). The resistivity value from the San Benito formation corresponds to the resistivity obtained from the TEM sounding. This new discovery has also been discussed in the study of Mårdh (2017) and must be further studied in order to corroborate the hypothesis.

In Fig. 6b, the horizontal resistivity distribution of $\mathrm{A} 2$ is displayed. Lower-resistivity values are found in A2 than in A1 most likely due to the fact that the clay content increases toward the distal part of the fan, where A2 is located. The brine zone is mainly located approximately at $2650 \mathrm{~m}$.a.s.l, and the resistivity in this zone is close to $0.1 \Omega \mathrm{m}$. The Punata alluvial fan is delimited by a clay fringe in the western portion (GEOBOL 1983; Gonzales Amaya et al. 2016). This fringe acts like an impermeable barrier whereby the brine cannot pass and therefore takes a southeastern dip direction.

The thickness of the low-resistivity brine layer in both areas is around $20 \mathrm{~m}$. The depth of investigation in A1 is close to $200 \mathrm{~m}$, while in A2 it is in average $130 \mathrm{~m}$. In A1, the bottom zone with high-resistivity values might be interesting for research purposes from an hydrogeological point of view since the high values of resistivity might represent the bedrock. It might be possible to find stored water in the water. In a, the tick dashed line indicates a possible fault line. In $\mathbf{b}$, the arrows resemble the dip direction of the saline water

bedrock which later can be exploited if a secondary porosity exists. Therefore, it is advisable to perform more studies such as geophysics and drilling in order to understand this zone better.

\section{Conclusions}

The TEM soundings agree well with the ERT surveys, chloride/sodium ion data, and geological logs from boreholes where comparison was possible. The top layers of the Punata aquifer system are composed mainly of coarser material, and it is the main geological unit for groundwater exploitation. The bottom of the aquifer system is composed of two layers: The first is a sandy clay with saline water content, while the deeper is a high clay content aquiclude, which is the bottom of the Punata aquifer system. The brine layer was not distinguished with previous ERT surveys, but it is detected with TEM.

The lacustrine bottom layers with high clay content dispersed the electromagnetic signals, and this restricted the depth of investigation to around 200 and $130 \mathrm{~m}$ reached in A1 and A2, respectively. Besides identifying brine zones in both areas, a possible fault line was detected in A1. This 
zone might be a possible lower aquifer, and in order to support this finding more studies are needed.

In general, the use of TEM assisted in delimiting a zone with brine within the Quaternary deposits of the Punata alluvial fan. The integration of other geophysical methods such as ERT and induced polarization improves the interpretation and characterization of aquifer systems. There are some aspects that still need more investigation, such as the determination of the bedrock depth and to confirm the possible fault line.

Acknowledgements The present study was supported by the Swedish International Development Agency (SIDA) in collaboration with Society of Exploration Geophysicist-Geoscientists Without Borders (SEG-GWB), Lund University (Sweden), Universidad Mayor de San Simon (Bolivia), and Aarhus University (Denmark). We are very grateful for all the support received. Special thanks to Esben Auken for providing valuable advice regarding layout design of TEM surveys and data interpretation and to the other people at Hydrogeophysics Group at Aarhus University who helped us. Thanks to Guideline Geo for supporting with equipment for TEM surveys. Also thanks to all the UMSS students who collaborated during the project.

Open Access This article is distributed under the terms of the Creative Commons Attribution 4.0 International License (http://creativecomm ons.org/licenses/by/4.0/), which permits unrestricted use, distribution, and reproduction in any medium, provided you give appropriate credit to the original author(s) and the source, provide a link to the Creative Commons license, and indicate if changes were made.

\section{References}

Alabi AA, Ogungbe AS, Adebo B, Lamina O (2010) Induced polarization interpretation for subsurface characterization: a case study of Obadore Lagos State. Arch Phys Res 1:34

Christensen NB, Sørensen KI (1998) Surface and borehole electric and electromagnetic methods for hydrogeological investigations. Eur J Environ Eng Geophys 3:75-90

Christiansen AV, Auken E, Sørensen K (2009) The transient electromagnetic method. In: Groundwater geophysics, vol 6. Springer, Berlin, Heidelberg, pp 179-226

Dahlin T (2001) The development of DC resistivity imaging techniques. Comput Geosci 9:1019-1029

Danielsen JE, Auken E, Jørgensen F, Søndergaard V, Sørensen KI (2003) The application of the transient electromagnetic method in hydrogeophysical surveys. J Appl Geophys 53:181-198

Eugster HP, Hardie LA (1978) Saline lakes. In: Lerman A (ed) Lakes. Springer, New York

Fitterman DV, Stewart MT (1986) Transient electromagnetic sounding for groundwater. Geophysics 51:995-1005
GEOBOL (1983) Estudio geologico de la hoja de Punata cuadrangulo No 6441. GEOBOL, La Paz, Bolivia

Goldman M, Neubauer F (1994) Groundwater exploration using integrated geophysical techniques. Surv Geophys 15:331-361

Goldman M, Arad A, Kafri U, Gilad D, Melloul A (1988) Detection of freshwater/seawater interface by the time domain electromagnetic (TDEM) method in Israel. Nat Tijdsehr 70:339-344

Gonzales Amaya A, Dahlin T, Barmen G, Rosberg J-E (2016) Electrical resistivity tomography and induced polarization for mapping the subsurface of alluvial fans: a case study in Punata (Bolivia). Geosciences 6:51

Guérin R, Descloitres M, Coudrain A, Talbi A, Gallaire R (2001) Geophysical surveys for identifying saline groundwater in the semi-arid region of the central Altiplano. Boliv Hydrol Process 15:3287-3301. https://doi.org/10.1002/hyp.284

Hardie LA, Eugster HP (1970) The evolution of closed-basin brines mineralogical. Soc Am Spec Publ 3:273-290

IPCC (2007) Climate Change and Water, Intergovernmental Panel on Climate Change. Technical Report IV World Meteorological Organization

Loke M (2010) Res2DInv ver 3.59. 102. Geoelectrical imaging 2D and 3D. Instruction manual. Geotomo Software

Loke MH, Acworth I, Dahlin T (2003) A comparison of smooth and blocky inversion methods in $2 \mathrm{D}$ electrical imaging surveys. Explor Geophys 34:182-187

Mårdh J (2017) A geophysical survey (TEM; ERT) of the Punata alluvial fan, Bolivia. Master Degree, Lund University

May J-H, Zech J, Zech R, Preusser F, Argollo J, Kubik PW, Veit H (2011) Reconstruction of a complex late Quaternary glacial landscape in the Cordillera de Cochabamba (Bolivia) based on a morphostratigraphic and multiple dating approach. Quat Res 76:106-118. https://doi.org/10.1016/j.yqres.2011.05.003

Mills T, Hoekstra P, Blohm M, Evans L (1988) Time domain electromagnetic soundings for mapping sea-water intrusion in monterey County, California. Gr Water 26:771-782

Montenegro E, Rojas F (2007) Potencial hidrico superficial y subterraneo del abanico de Punata. Universidad Mayor de San Simon, Cochabamba

Nabighian MN (1991) Electromagnetic methods in applied geophysics: volume 2, application, parts A and B. Society of Exploration Geophysicists

Nabighian MN, Macnae JC (1991) Time domain electromagnetic prospecting methods Electromagnetic methods in applied geophysics 2:427-509

Revil A, Binley A, Mejus L, Kessouri P (2015) Predicting permeability from the characteristic relaxation time and intrinsic formation factor of complex conductivity spectra. Water Resour Res 51:6672-6700

Slater LD, Lesmes D (2002) IP interpretation in environmental investigations. Geophysics 67:77-88

UNDP-GEOBOL (1978) Proyecto Integrado de Recursos Hidricos. Cochabamba, Bolivia 